\title{
Research on Heat Meter Wireless Reading System in Living Area
}

\author{
Yushen $\mathrm{JIA}^{\mathrm{a}}$, Zhenjiang CAI ${ }^{\mathrm{b}, *}$, Yao YU
}

College of Mechanical \& Electrical engineering, Agricultural University of Hebei, Baoding,071000, China

aemail: 316351048@qq.com, bemail: czj65@163.com, "corresponding author

Keywords: Heating System, Heat Meter, Concentrator, Remote Automatic Meter Reading

\begin{abstract}
In order to improve the heating system's intelligence and automation level, a wireless remote meter reading system is designed based on GPRS network technology. The system consists of heat meters, collector, concentrator and remote management centers. The hardware is constructed by STM32F103MPU, wireless module, GPRS module and other components, using a combination of GPRS and wireless communications network. The software of management centers includes remote meter reading system and energy data management system, realizing the functions of remote meter reading, data query, CSV downloads, real-time monitoring and so on. The system, adopting C\# and PHP hybrid programming, achieves program lock by program itself and therefore prevents database lock and also provides multi-thread meter reading. According to the test results, the system is characterized by a simple structure, low cost and a wide range of application, therefore it has a good market value and bright prospects for application.
\end{abstract}

\section{Introduction}

As society develops, people's demand on comfortable living environment is increasingly high. In northern China, the indoor temperature during winter is mainly adjusted by the heating system. However, heating service charge in China is usually based on housing area and heating period instead of the actual heat consumption, and thus impacting users' initiatives to pay ${ }^{[1]}$. It results in heating companies unable to collect fees on time and finally serving the users in a bad manner or providing no service at all ${ }^{[2]}$.As early as the 1980s, Europe, the U.S., Japan and other developed countries had conducted a pilot study on remote meter reading system, and achieved power remote meter reading and load control in power companies ${ }^{[3-5]}$. Nevertheless, heat meter remote meter reading started relatively late and mostly referred to the power meter reading system. In article 6 , the remote automatic meter reading system achieves some visual controlling command such as remote uploading meter data, data receiving, charges and query. In article 7, management functions in the entire system such as data acquisition, remote reading, data processing and alarm processing are realized based on GPRS wireless communication.

Nowadays, most remote meter reading managing systems adopt a single transfer mode. In order to save the hardware and running costs, this article designs a wireless meter reading system with the combination of GPRS and wireless radio frequency.

\section{System hardware architecture}

The heat meter remote reading management system is built up mainly by the management center, GPRS wireless communication network, concentrator, collector and heat meters. System hardware diagram is shown in Figure 2.1. The heat meter data is collected by the collector; then upload the collector's data to the concentrator and transfer the data to the concentrator by wireless network; and finally upload the data to heat manage center through GPRS. Concentrator is the key part of the remote meter reading system and its hardware block diagram is shown in Figure 2.2. STM32F103 MPU is the core unit which is used to receive controlling command, issue order to collectors, receive data from collectors and store them. GPRS module is used to communicate between concentrator and the main site while the wireless radio frequency module is used to communicate 
between meter and the concentrator.

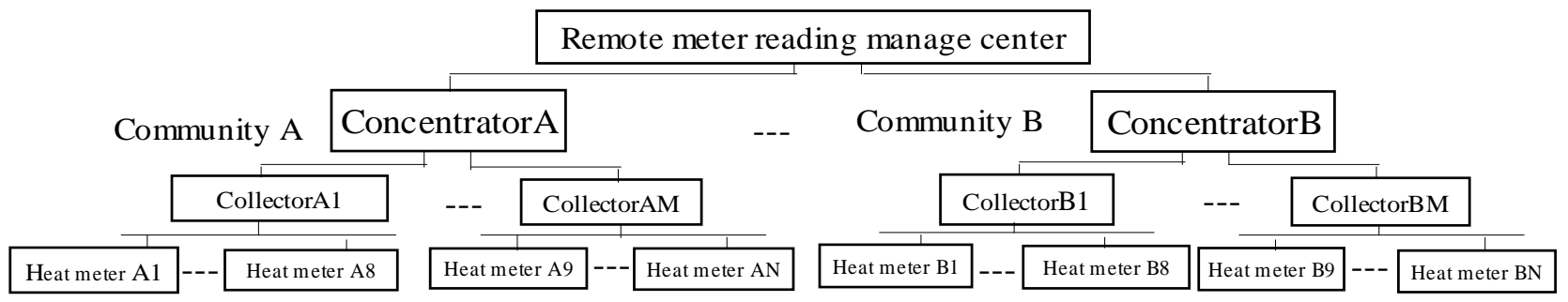

Figure 2.1.Overall system architecture diagram

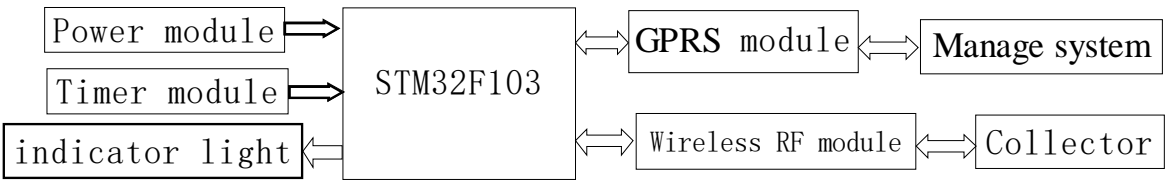

Figure 2.2 Concentrator hardware block diagram

\section{System software design}

The system software is divided into two parts: the remote meter reading system and data management system. Remote meter reading system is written with C\#, which structures the TCP server, reads and saves the meter data. The data management system uses Apache + PHP server for remote meter reading control and data query, CSV (Comma-Separated Values) downloading and the system settings. The system software structure is shown in Figure3.1.

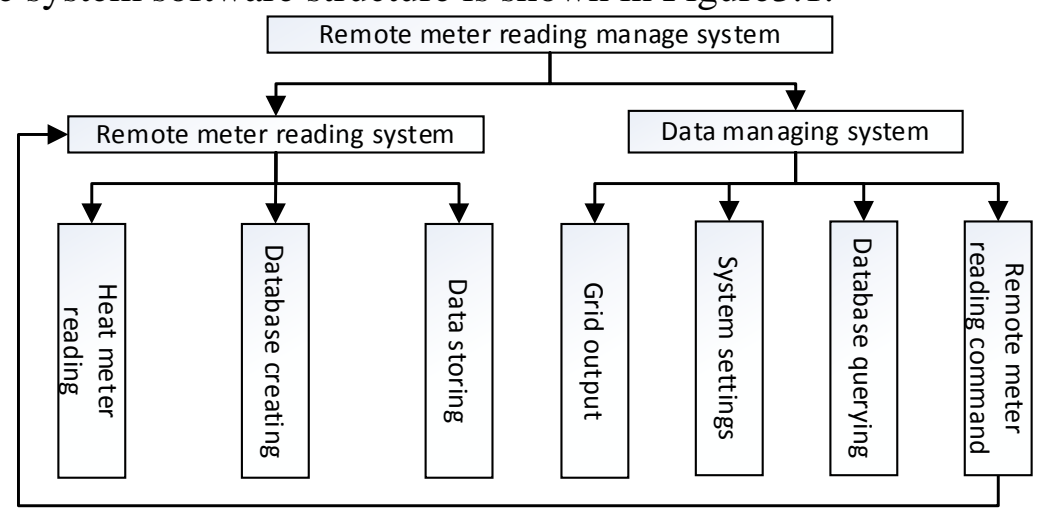

Figure3.1. System software structure

\subsection{Remote meter reading system}

In accordance with the object-oriented development concept, the classes of the entire system are designed first. The meter reading system includes a class that manages the client, an abstract class Misc and several internal threads. The client management class is named class MeterManager which is used to manage concentrator clients. A concentrator client is a MeterClient class, which inherits from the TCPClient class of Socket class ${ }^{[8]}$, which is a TCP client. C\# uses it to transmit data with a client. After inheriting, MeterClient class adds a community code attribute. When a new MeterClient is created, the system automatically starts a new thread to begin processing sending and receiving streams.

For ease of operation, the system defines an abstract class Misc to embody the reusable methods of the program. The structure of the remote meter reading system is shown as Figure 3.2. 


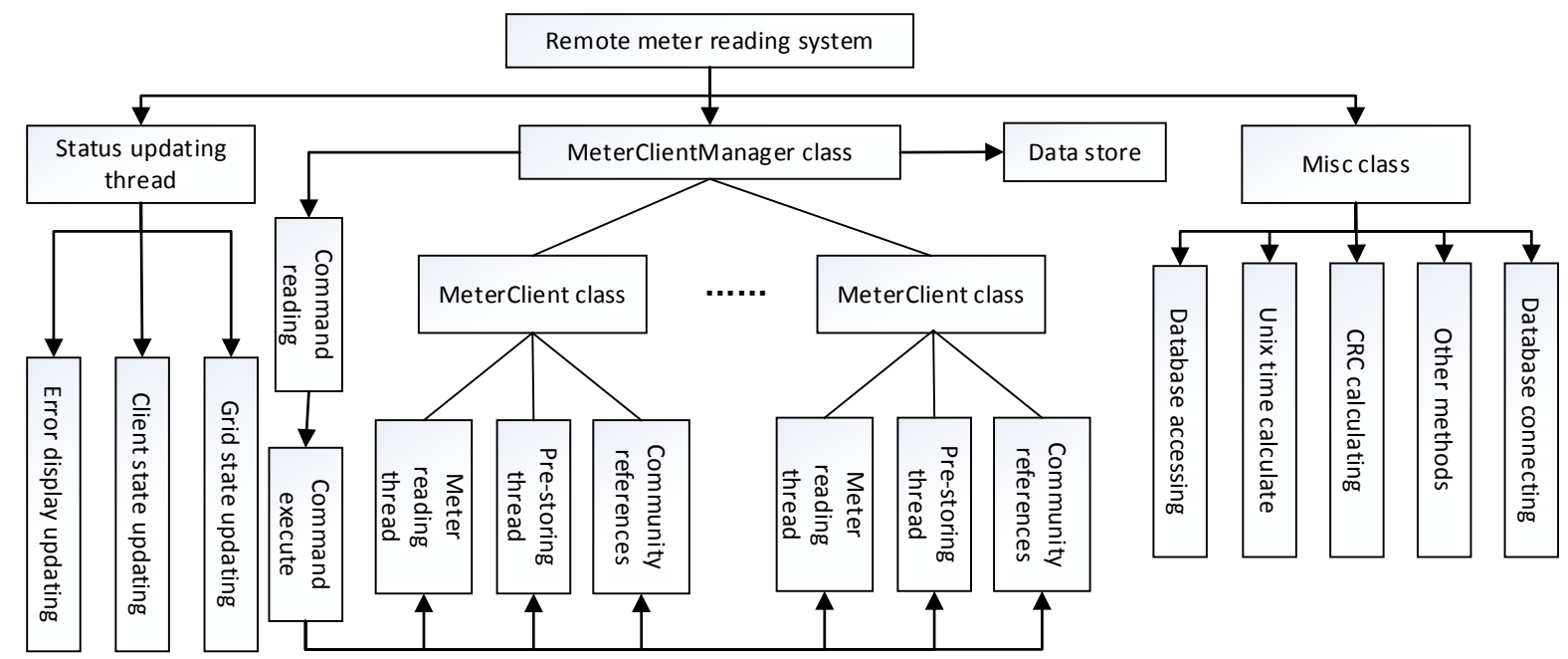

Figure 3.2 The structure of the remote meter reading system

\subsubsection{State updating thread}

In order to monitor meter reading process real-time, the program uses GridView to list the concentrator states. Two Textbox display the data from the heat meter, the data sent to the heat meter and the error message in real-time. To let it display in real-time, the program also opens a thread to update the interface, reads the cached information from MeterClientManager class, displays them in the message box and clears the cache.

\subsubsection{MeterClientManager class}

MeterClientManager class is the core of the remote meter reading system, shouldering commanding processing, meter thread management and data storage functions. Each new client connections builds a MeterClient class, and starts managing them after reading the community code successfully. MeterClient contains meter reading threads, pre-storing thread and community properties $^{[9]}$.

When the meter reading starts, the data in the database is read to determine the reading range and then the meter will be read successively. Each time the system receives a reply message, it will store it in the database and start to read the next if the replying message is correct meter data, otherwise it will read the meter again. And this also applies if there is no answer in 3 seconds. However, if reading is still unsuccessful for three times, the system will skip the meter and mark a failure.

After the system starts, a handshake packet from concentrators is waited first. A handshake packet is 3 bytes long. The first byte is $0 x E E$, then a two-byte of the community code. The TCP server should respond with a heartbeat packet if a heartbeat packet or a handshake packet is received. Heartbeat packages every of which is sent every 30 seconds under normal circumstances are used to ensure that the clients do not disconnect the connection. A heartbeat packet is sent again if TCP server's response is received. If three consecutive heartbeat packets do not response it is determined that the connection is disconnected.

When the meter is read, a reading packet is sent. A reading packet is constructed by several parts to order the concentrator to read a specified meter. The concentrator responds with a corresponding data packet after receiving the reading packet. The reading packet's structure is shown in Table1; the data packet's structure is shown in Table2.

Since the SQLite database can only be accessed by one source at the same time, it needs to minimize the amount it reads. The MeterClient class data is not stored in the database instantly but the obtained reading packets are saved in the Dictionary by the pre-store thread and wait to be dealt with by MeterManager. When a large quantity is stored in the SQLite database, the transaction is used, which can greatly reduce the deposit time, improve efficiency and avoid locking when the threads simultaneously access the database. 
Table1 Reading package structure

\begin{tabular}{|c|c|c|c|c|c|}
\hline Position & Content & Position & Content & Position & Content \\
\hline 1 & 0x0F & 5 & 0x00 & 9 & Meter address \\
\hline 2 & $\begin{array}{c}\text { Community } \\
\text { code }\end{array}$ & 6 & 0x02 & 10 & CRC16 \\
\hline 3 & $0 x 00$ & 7 & 0x02 & 11 & CRC16 \\
\hline 4 & 0x02 & 8 & 0x01 & & \\
\hline
\end{tabular}

Table2 Data packet structure

\begin{tabular}{|c|c|c|c|c|c|}
\hline Position & Content & Position & Content & Position & Content \\
\hline 1 & 0xF0 & 16 & Energy data & 31 & Volume data \\
\hline 2 & Community code & 17 & Energy data & 32 & Volume data \\
\hline 3 & Concentrator code & 18 & Energy data & 33 & Volume data \\
\hline 4 & Concentrator code & 19 & Energy data & 34 & 0x3B \\
\hline 5 & Concentrator code & 20 & 0x07 & 35 & Water temperature data(in) \\
\hline 6 & Concentrator code & 21 & Flow data & 36 & Water temperature data(in) \\
\hline 7 & Collector code & 22 & Flow data & 37 & 0x5A \\
\hline 8 & Collector code & 23 & Flow data & 38 & Water temperature data(out) \\
\hline 9 & Meter number & 24 & Flow data & 39 & Water temperature data(out) \\
\hline 10 & Meter number & 25 & Flow data & 40 & 0x5E \\
\hline 11 & Meter number & 26 & 0x14 & 41 & Sensor status \\
\hline 12 & Meter number & 27 & Energy data & 42 & 0xFF \\
\hline 13 & Meter address & 28 & Energy data & 43 & 0xFF \\
\hline 14 & 0x77 & 29 & Energy data & 44 & CRC16 \\
\hline 15 & 0x04 & 30 & 0x2D & 45 & CRC16 \\
\hline
\end{tabular}

\subsubsection{Misc class}

Misc class encapsulates the necessary functions for the unified treatment of various types of miscellaneous services including CRC verification, Unix time computing and so on. In addition, except for the necessary long access, all connection behaviors are summarized in the Misc class. Mandatory release is achieved through other open thread to avoid causing that the resource is stuck when read and cannot be promptly released.

\subsection{Data manage system}

The data manage system needs to support query according to a community or a cell door and also needs to query all data. In addition, it also needs to be able to export the detected data as a spreadsheet file for easy access and analysis of finishing. The structure of the data management system is shown in the following figure 3.3.

The meter control function send commands to a remote meter reading system to achieve control of the meter reading behavior. Remote meter reading system is responsible for receiving commands and reading ${ }^{[10]}$. The data query function questions all data for the entire database. Special inquiry is an advanced data query function to inquire data in the database according to a concentrator or a collector. System settings can adjust various parameters of the system including the timing meter intervals and the password. Encoding function in a cell can achieve the export of a report, which facilitates the summarizing and finishing of the data. 


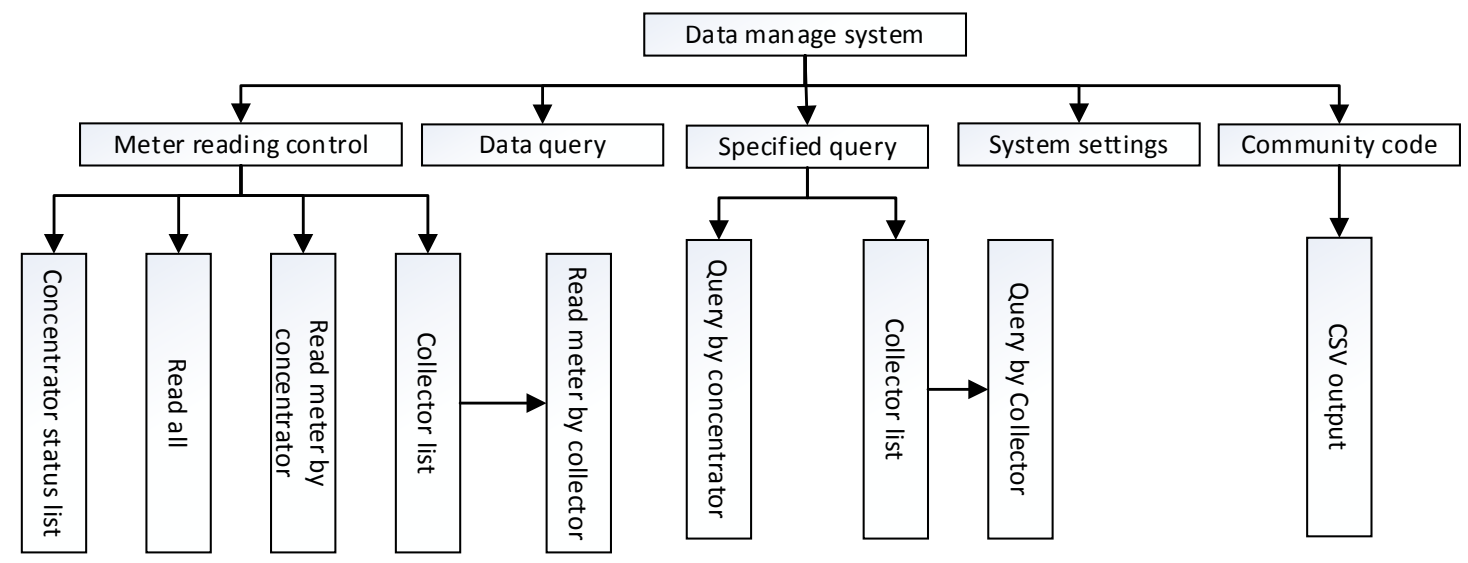

Figure 3.3 Structure of the data management system

\section{System testing}

First, the system function of creating database is tested. The existing database is deleted and software metering is run. The software establishes a database according to the established structure. The database's structure is opened and checked through SQLite database software as Figure 4.1.

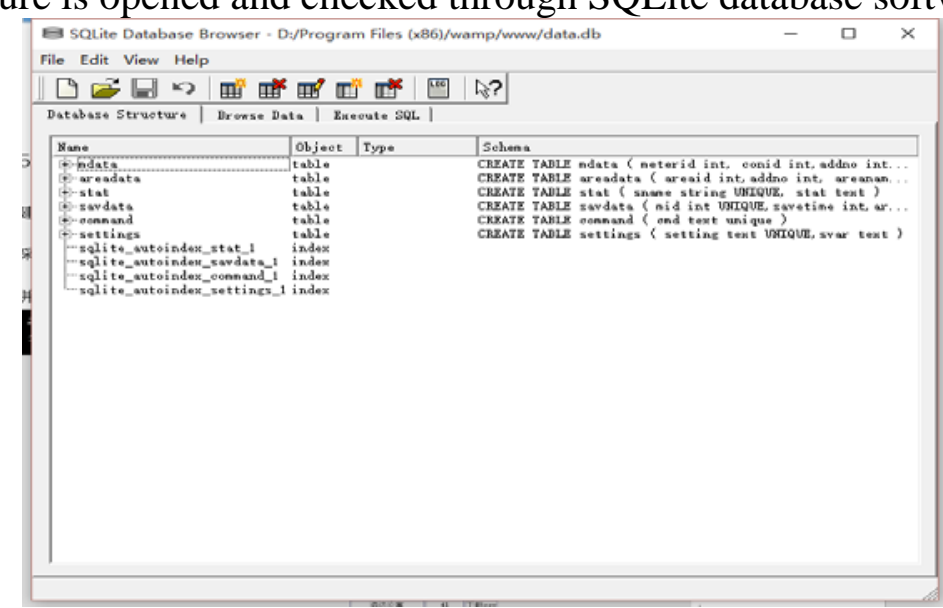

Figure 4.1 Database structure

All heat meters are read and the obtained data is stored into the database. Respectively according to a concentrator (community) and a collector, meters are read. And all the meters are read at one time. The content of the database is check to determine whether it is valid or not. System settings are modified in the settings management section and saved. And whether the function is valid or not is confirmed. The reading functions of the system including reading by a concentrator, by a collector and all meters and paging function are tested separately. And the data is attempted to be downloaded with CSV format. Through the above test, the results are shown in Table 3.

\section{Conclusion}

The system uses wireless communication in the community and GPRS between the communities and the manage center. It improves the real-time system, reduces the cost of communication. The software is designed with C\# and PHP of hybrid programming, which allows the system to run on any computer that supports PHP and .NET Framework. Apache / IIS / nginx server and PHP are needed to be configured only without the need of installing SQL Server. Test results show that: the system features stability, reliability, ease to use, low cost, wide application and network convenience. It achieves a wireless remote meter reading function with good value and market prospects. 
Table3 Data manage module test result

\begin{tabular}{|c|c|c|c|c|}
\hline Function module & \multicolumn{4}{|c|}{ Data manage module } \\
\hline Function & \multicolumn{4}{|c|}{ Exchange data with database and meter reading system } \\
\hline Testing propose & \multicolumn{4}{|c|}{ Whether the functions are running properly } \\
\hline Test steps & $\begin{array}{l}\text { Operation } \\
\text { description }\end{array}$ & Action & Expected results & Result \\
\hline 1 & $\begin{array}{l}\text { Database } \\
\text { creating }\end{array}$ & $\begin{array}{l}\text { Read access } \\
\text { database and create } \\
\text { SQLite database }\end{array}$ & $\begin{array}{l}\text { Create database successfully } \\
\text { and set the settings to default }\end{array}$ & $\mathrm{OK}$ \\
\hline 2 & $\begin{array}{l}\text { Read meter by } \\
\text { concentrator } \\
\text { and collector }\end{array}$ & Read meter data & $\begin{array}{l}\text { Read properly and save the } \\
\text { received data into database }\end{array}$ & $\mathrm{OK}$ \\
\hline 3 & $\begin{array}{c}\text { Setting } \\
\text { managing }\end{array}$ & Database accessing & $\begin{array}{l}\text { Do system settings and } \\
\text { password changing } \\
\text { successfully }\end{array}$ & $\mathrm{OK}$ \\
\hline 4 & $\begin{array}{l}\text { Query meter } \\
\text { data }\end{array}$ & Data query & $\begin{array}{c}\text { Query meter data by multi } \\
\text { ways; CSV file downloading } \\
\text { support }\end{array}$ & $\mathrm{OK}$ \\
\hline
\end{tabular}

\section{References}

[1]Sun Jing-wei. Energy conservation running of urban heating [J]. chinachizi， 2012 (6): 218-218

[2]Li Yong-hong. The problems about central heating household metering heating costs [J]. Heilongjiang Science and Technology Information,2008, 15:106.

[3] Khalifa T, Naik K, Nayak A. A survey of communication protocols for automatic meter reading applications[J]. Communications Surveys \& Tutorials, IEEE, 2011, 13(2): 168-182.

[4] Hsia S C, Hsu S W, Chang Y J. Remote monitoring and smart sensing for water meter systemand leakage detection[J]. Wireless Sensor Systems, IET, 2012, 2(4): 402-408.

[5] Shen Cheng-qing..Design of Wireless Remote Meter Reading System for Diaphragm Gas Meter[D]. Chongqing University, 2012.

[6]Zhang Chang-zhi .Study and Development of Automatic Meter Reading System[D]. Nanjing University of Science \&Technology,2012.

[7]Chen Shu-shen,Yang Hai-xia.The application of GPRS remote readingmeter and energy management system[J]. Energy Conservation,2012,3:60-63

[8] Storimer ,Jesse. Working with TCP sockets [M]. Beijing : Posts and Telecom Press ,2013

[9] Gungor V C, Sahin D, Kocak T, et al. Smart grid technologies: communication technologies and standards[J]. Industrial informatics, IEEE transactions on, 2011, 7(4): 529-539.

[10] Gao Fu-xiang, Xue Wenxin, Liu Langtao. Overview on remote meter reading system based on GPRS,Second International Conference on Industrial and Informaion Systems(IIS 2010)[C], 2010, 270-273. 